\title{
Projecting Aridity from Statistically Downscaled and Bias Corrected Variables for Gediz Basin/Turkey
}

Umut Kirdemir ( $\nabla$ umut.kirdemir@gmail.com )

Balikesir Universitesi https://orcid.org/0000-0001-5336-4842

\section{Umut Okkan}

Balikesir University

\section{Research Article}

Keywords: Statistical downscaling, aridity index, equidistant quantile mapping, Bayesian Model Averaging

Posted Date: March 19th, 2021

DOI: https://doi.org/10.21203/rs.3.rs-299536/v1

License: (1) This work is licensed under a Creative Commons Attribution 4.0 International License. Read Full License 


\title{
PROJECTING ARIDITY FROM STATISTICALLY DOWNSCALED AND
}

\section{BIAS CORRECTED VARIABLES FOR GEDIZ BASIN/TURKEY}

\author{
Umut Kirdemir ${ }^{\mathrm{a}, \mathrm{b} *}$ and Umut Okkan ${ }^{\mathrm{b}}$ \\ a Department of Civil Engineering, Dokuz Eylul University, Izmir, Turkey, \\ ${ }^{\mathrm{b}}$ Department of Civil Engineering, Balikesir University, Balikesir, Turkey
}

*Correspondence to : Dr. Umut Kirdemir, Department of Civil Engineering, Hydraulic

Division, Balikesir University,10145, Balikesir/Turkey.

E-mail: umut.kirdemir@gmail.com

ORCID (iD https://orcid.org/0000-0001-5336-4842

\begin{abstract}
In recent years, significant temperature increase all across of the world draws attention and climate regimes are shifting in different parts of the world. By the reason of these climatological changes, a study was conducted in Gediz Basin/Turkey, where agricultural production has an important place. In the study prepared, twelve GCMs were utilized under RCP4.5, RCP6.0 and RCP8.5 scenarios of 5th Assesment Report of IPCC for the period 2015-2050. The statistical downscaling methods were employed and the projections were derived right after applying weighted-averaged ensemble mean by Bayesian Model Averaging method and bias correction by equidistant quantile mapping method. The temperature-based potential evapotranspiration formulas were modified in accordance with PenmanMonteith method and the aridity indexes were calculated by UNEP (1992). According to the projections, the mean annual temperature increases between $1.5^{\circ} \mathrm{C}$ and $2.2^{\circ} \mathrm{C}$ and mean total annual potential evapotranspiration increases between 5\% and $8 \%$ are foreseen in Gediz Basin for the near future. It is foreseen that semi-arid climate regime may predominate over the region for all of the RCP scenarios under the increasing dryness in basin climate. In addition, it was obtained in the study that sub-humid climate state occurance for all of the regions included by the basin may be unexpected in the future for
\end{abstract}


RCP8.5 scenario. The presence of semi-arid climate conditions may be more potent with the increasing trend of radiative forcing over time.

Keywords: Statistical downscaling, aridity index, equidistant quantile mapping, Bayesian Model Averaging.

${ }^{*}$ Correspondence to: Umut Kirdemir, Department of Civil Engineering, Hydraulic, Hydrology and Water Resources Division, Dokuz Eylul University, 35160, Izmir/TURKEY. E-mail: umut.kirdemir@gmail.com

\section{Introduction}

Earth climate is reacting to human activities conspicuously and becoming the world's most important issue to be dealt with by all countries. Climate patterns are changing day by day in consequence of anthropogenic effects which are originated from especially energy requirements. These requirements cause the greenhouse gas (GHG) emmissions, hence, the temperature is gradually increasing in various parts of the earth. Moreover, there are several up-to-date researches which capture the increasing temperature. For instance, Intergovernmental Panel on Climate Change (IPCC) (2013) reported that the 30-year period between 1982 and 2012 represents the hottest observed period. World Meteorological Organization (WMO) (2017) announced that the year 2017 was ranked as one of the three warmest consecutive years. According to the prepared report, 2016 is the first, 2017 is the second and 2015 is the third warmest years which have been ever recorded for the earth. Additionally, National Oceanic and Atmospheric Administration (2019) released that the increasing temperature trend kept going in 2018 and it was ranked as fourth warmest year among the annual records. In the light of these notifications, especially the peak temperature 
events recently experienced consecutively across the world, led the authors to investigate how the climate regime might change in the future.

In the climate change studies, the mathematical models which capture the Earth's physical climate system, the general circulation models (GCMs), are the most frequently utilized tools to predict the past and future climate. The GCM data with coarse resolution are not enough to represent the local climate of a specific region, hence, the downscaling techniques are highly recommended by climate scientist so as to derive precise estimates. It is important to monitor climate change so that the relevant authorities may take measures against natural hazards such as droughts, floods, tornadoes, and etc. which are induced by unbalanced climatological shifts. One of them, droughts, can be defined as a normal climatological event which can occur in every type of climate regime, however, it can be more severe in arid regions (Smakhtin and Schipper, 2008). In the literature, those ideas can sometimes intermingle with one another, drought and aridity. Drought is considered as a notion of temporary events, this is why it is called as a natural hazard but undergone more slowly than others, whereas aridity is a longterm climate condition which generally specifies the climate state of a region. Hence, the reason of aridity is significant within the scope of climate change (Maliva and Missimer, 2012). The aridity can be indexed by means of several methods which are mainly the functions of precipitation $(\mathrm{P})$, temperature $(\mathrm{T})$ and temperature-related potential evapotranspiration (PET). In the related literature, it is possible to encounter many downscaling implementations relevant to $\mathrm{P}$ and $\mathrm{T}$ variables. However, the number of studies concentrating on the derivation of the aridity indices from the downscaled $\mathrm{P}$ and $\mathrm{T}$ projections is rather limited (e.g, Lin et al., 2018; Yin et al., 2015; Dascălu et al., 2016). Moreover, several studies about determination of aridity index (AI) and evaluation within the scope of climate change are as follows. For instance, Marengo and Bernasconi (2015) prepared a study about climate change projections over Brazil and tried to predict the AIs until 2100 by means of a regional model integrated HadCM3 
climate model under A1B emmission scenario. The AIs proposed by Budyko (1958) and United Nations of Environmental Programme (UNEP) (1992) were used in their study to determine historical and future aridity of Brazil. They estimated negative effects in terms of meteorological variables and did not detect any significant difference between the indexes until 2071. Nastos et al. (2013) made a projection study in Greece by means of eight regional climate models (RCMs) run under SRES A1B. They weighted the climate models with regard to their performances and obtained an ensemble model. Also, they utilized interrelated AIs which were UNESCO (1979) and UNEP (1992), and found drier spells which may take place in the future for both of them. In addition to above-mentioned studies prepared under CMIP3 data set, there are projections derived under CMIP5 data set. For instance, Scheff and Frierson (2015), used sixteen GCMs employed under RCP8.5 scenario and the ratio of P and PET to obtain the AI for the regions of America, India and South Africa. They used Penman-Monteith method to calculate PET and provided information about possible expansion of aridity in the future. Fernandez et al. (2017) used Koppen-Trewartha climate classification method to label possible climate regime in the future and vegetation cover as well. They utilized ensemble mean of four RCMs under RCP8.5 and found aridification signals over South America.

In this study, it is desired to investigate possible future AIs over Gediz Basin, an important basin where agriculture has the biggest allocation in the production sector. The up-to-date climate models derived under IPCC's last assesment report, AR5, was taken into account. Three scenarios related to future GHG stabilization named as Representative Concentration Pathways (RCPs) were utilized. Twelve GCMs under two mid-stabilization scenarios RCP4.5, RCP6.0 and high-stabilization scenario RCP8.5 were employed. A novel methodological strategy was applied by means of downscaling/multi model ensemble/bias correction strategy which will be discussed in Methodology section and the projections were obtained for the period 2015-2050. Projections which were prepared for this study has three processes: a) Simulation of 
precipitation and temperature, b) simulation of potential evapotranspiration and c) simulation of AI for the term 2015-2050.

In fact, any aridity projection work under RCP scenarios has not been exercised for the basin of Turkey. This is one of the outstanding aspects of the paper. Another novel aspect is the development of a temperature-based PET approach that simulates the Penman-Monteith predictions, and thus converting the RCP scenario-based T projections into PET and aridity projections. The proposed methodological strategy is thought to provide a practical way for researchers interested in the subject. In remaining part of the paper, the results which were achieved under different RCP scenarios were evaluated and finally, conclusion part with a thorough discussion was given.

\section{Study area and data}

The study area is Gediz Basin which is located in the western part of Turkey. Gediz Basin is named by the Gediz River with $401 \mathrm{~km}$ long river reach and having drainage area of 17125 $\mathrm{km}^{2}$. The river rises from Murat Mountain of Kutahya region in the east and flows into Aegean Sea in the west. The study area has a typical Mediterrenean climate. The most of the population existing in the basin lives off agricultural sector. Agricultural productions are made in irrigated fields with the area of 110000 ha which extends from south to west of the basin. In the study, the data of 20 meteorological stations which observe both $\mathrm{P}$ and $\mathrm{T}$ were utilized for the time period between January 1980 and December 2005 and the data archive are provided from Turkish Meteorological Service (TMS) (Table 1, Figure 1). According to the data, the mean areal $\mathrm{P}$ is observed as $550 \mathrm{~mm}$ per year and mean annual $\mathrm{T}$ is observed as $13^{\circ} \mathrm{C}$.

In the climate change studies, the reanalysis data which represent the atmospheric, oceanic and land surface state of the past time are utilized frequently. In this work, ERA-Interim reanalysis 
data were used so as to determine predictor variables of the Gediz Basin T and utilized as inputs in downscaling applications. The reanalysis data set covers Gediz Basin between $37.875^{\circ}$ $39.375^{\circ} \mathrm{N}$ latitudes and $26.625^{\circ}-29.625^{\circ} \mathrm{E}$ longitudes with the resolution of $0.75^{\circ}$ in both axis. The selected time period of the reanalysis data is same as T data obtained from TMS.

In this study, the climate scenarios referred to in IPCC's last assessment report (AR5) was taken into account. In AR5, Representative Concentration Pathways (RCPs) in which the radiative forcing forecasts are made for 21 st century and after are constituted by means of different emmission scenarios. In the work, the mid-stabilization pathways RCP4.5 and RCP6.0 and high stabilization pathway RCP8.5 scenarios were taken into consideration for this study. The optimistic scenario RCP2.6 where it is foreseen radiative force of $2.6 \mathrm{~W} / \mathrm{m}^{2}$ by the end of 2100 was not evaluated because it is desired to seek the climate in the conditions of increasing radiative forcing and greenhouse gas emmissions. The Coupled Model of Intercomparison Phase 5 (CMIP5) data set of twelve GCMs were utilized for the related RCP scenarios. Though more than 30 GCMs were present in the CMIP5 archive, some GCMs were eliminated through minding the compatibility between the variables in the reanalysis and GCM data sets. Anandhi et al. (2008) and Okkan and Inan (2015) recommended the usage of Kendall's Tau nonparametric rank correlation statistics to detect the relationship between reanalysis predictors and historical scenario results of GCMs, and uttered that this statistics has expediencies comparable with other indices. In the study, the GCMs, in which the rank correlation statistics were less than or equal to 0.3 , were ruled out and as a result, it was decided to utilize 12 GCMs that were also listed in Okkan and Kirdemir (2016). The computational details about the GCM based rank indicators were not shared in the paper due to the limitation of word number. Although it was possible to access the data of whole of 21 st century, the projection period was decided as the years between 2015 and 2050 such that it was considered that predictions are less uncertain for the near future. Moreover, in addition to data of RCP scenarios, historical 
period data were utilized as the reference scenario (REF) which represents past climate over the region. By the reason of reference period for all of GCMs is commonly provided as in between 1980 and 2005, the same time period was chosen for both ERA-Interim reanalysis and observed TMS data. In GCMs, the atmospheric variables at different atmospheric levels are selected same as those of ERA-Interim reanalysis data set so that selected predictors via reanalysis data could be used analogously at the stage of downscaling GCMs. The related atmospheric variables exist in both reanalysis data and GCMs are mean air temperature (air), sea level pressure (slp), large-scale precipitation (pr) at surface level, mean air temperature and geopotential height at atmospheric levels of $200 \mathrm{hPa}, 500 \mathrm{hPa}$ and $850 \mathrm{hPa}$ (air200, air500, air850, hgt200, hgt500, hgt850) and relative humidity at atmospheric levels of $500 \mathrm{hPa}$ and 850 $\mathrm{hPa}($ rhum500, rhum850).

The purpose of the study is to determine the AIs of Gediz Basin in the future. The methodology set up for this purpose requires projection of the $\mathrm{P}$ for the related time period and these data were extracted from Okkan and Kirdemir (2016) (hereinafter referred to as OK16). In OK16, the projection of P over Gediz Basin was derived for RCP4.5, RCP6.0 and RCP8.5 scenarios. The information about precipation projections prepared over Gediz Basin will be given in Results section. Moreover, the details of GCMs used in this study can be accessed from OK16.

\section{Methodology}

\subsection{Downscaling of GCM data}

General circulation models that are relatively coarse in terms of resolution are not efficient to capture the meteorological effects of climate change in the station scale. For this reason, high- 
resolution results are needed to interpret the effect of coarse-resolution atmospheric models in the station scale. Due to this requirement, it is possible to achieve a data set that more reliably represents the climatic characteristics of the study area by downscaling the coarse-resolution GCM data to the local scale using the downscaling method.

The downscaling models are divided into two as dynamical and statistical. Among them, the dynamical downscaling method involves applications based on physical climate models operating at regional scale. These models can be employed at higher resolutions, which also reflect topography features. Thus, orographic precipitation, extreme processes, and climatic anomalies in regional measurements can be taken into account with regional climate models. However, these models require too much input, contain too many parameters, and use coarse output of global-scaled models as initial-boundary conditions. With uncertainties from globalscaled models and high quantity in their own degrees of freedom, bias and uncertainty in predictions are increasing. In this respect, the implementation, setup and performance validation of these models are troublesome, which limits the applicability of these models. (Najafi et al., 2011). For these reasons, statistical downscaling methods based on the approach of developing numerical relations between large atmospheric variables and variables measured at the station scale are regarded as more user-friendly tools. Besides, in a study conducted in New Zeland by Le Roux et al. (2018), statistical and dynamical downscaling models were compared and it was concluded that it was more logical to use statistical downscaling models as it needs less computational effort although both models had close results to each other. By virtue of these reasons, statistical downscaling methods were preferred to dynamical downscaling methods for the projections in this study. However, it should be noted that a qualified statistical downscaling model requires that various assumptions are met. These assumptions, which were earlier mentioned by Schoof (2013), can be briefly listed as follows: 
a. There is a robust relationship between the predictors and the predictand (i.e., the variable being downscaled).

b. The predictors are sufficiently simulated by the GCMs.

c. The predictors incorporate the signal pertaining to climatic change.

d. The relationship between the predictors and predictand show stationary behavior.

The readers can look through the study of Schoof (2013) for the caveats of statistical downscaling methods and the detailed explanations about the assumptions listed above.

Artificial neural networks (ANN) and least squares support vector machines (LSSVM) methods were used for statistical downscaling to derive $\mathrm{T}$ projections. $\mathrm{P}$ projections were already obtained from OK16, hence it will be elucidated how to get $\mathrm{T}$ projections in this study. In both models, re-analysis variables were introduced as model inputs so that coarse-resolution GCM data could be downscaled to station scale. During the application of the downscaling models, it is aimed to define predictor data sets representing the observed $\mathrm{T}$ in the study area in order to reduce the computational cost. To apply this, all possible regressions (APREG) method was used and 12 ERA-Interim re-analysis variables as predictors and $\mathrm{T}$ observations of 20 meteorological stations as predictands were utilized in the related method. For the predictor selection, $2^{12}-2=4094$ regression models were established and the most suitable data set to be used as input in the downscaling model was selected according to the two performance criteria: one of them is root mean square error which indicates a derivation of average error stemmed from each submodels and the other one is Mallow's Cp that its relatively smaller values represents the smaller amount of bias in the predicted responses yielded by submodels. It was obtained when APREG method was employed that the regression model with only large-scale air temperature (air) variable showed a high correlated result with observed $\mathrm{T}$ variable for each 
meteorological station (approximately represents $99 \%$ of dependent variable variance for each station). As a result, it is sufficient to use the air variable of the re-analysis data as the $\mathrm{T}$ predictor of the stations. As with this study, only prate variable was selected as potential predictor of $\mathrm{P}$ in OK16, so it can be evaluated that prate and air variables of ERA-Interim data set are prominent variables in representing of $\mathrm{P}$ and $\mathrm{T}$ for Gediz Basin.

In the employing of ANN model, z standardization were applied for time series and LevenbergMarquardt algorithm were used for optimizing network's weights. In the employing of LSSVM model, the same standardization procedure were applied and, regularization parameter and radial basis function width of the model were calibrated.

Performance of downscaling models were evaluated by means of statistical performance criteria such as determination coefficient $\left(\mathrm{R}^{2}\right)$, RMSE, RSR which is proportion of RMSE to standard deviation of observed data and percent of bias (PBIAS) which is the metric of overestimation or underestimation. The theoretical knowledge about the related performance criteria is detailed in Moriasi et al. (2007).

\subsection{Multi-model ensemble and bias correction strategy}

When the climate models are taken into consideration, it can be stated that they have effective roles on projecting the future climate. Even if they are practical tools for climate scientists, the uncertainty still exists about the extent to which a single climate model can represent the climate of the related region. Regarding to this issue, it was recommended by Knutti et al. (2010) that combination of multiple general circulation model results can be applied in climate projection studies by averaging or weighting the model predictions. Besides, Kwon et al. (2010) compared several ensemble results of $\mathrm{T}$ projections over East Asia and they achieved more feasible and 
explanatory results with weighted ensemble model which were obtained by using Bayesian Model Averaging (BMA). Moreover, Yang et al. (2012) prepared a study for Tibetan Plateau and evaluated BMA and arithmetic mean method (equally weighted) for multi-model ensemble projections and they obtained more consistent results with BMA in comparison with arithmetic mean method. Similarly, better performing results obtained by utilizing BMA were presented in Min et al. (2007) and Miao et al. (2013) in which BMA-weighted and equally weighted results were compared. Moreover, OK16 employed BMA for P projections over Gediz Basin and derived simulations with higher significance levels than those of individual models. In the light of these informations, use of BMA method was decided by the authors for T projections in the study.

Raftery et al. (2005) proposed BMA to reduce uncertainty in model selection by combining multi-model forecasts. The model depends on weighting of probability density function (PDF) of each individual model forecasts, subsequently the weighted-average forecast PDFs can be derived. In the model, PDF of a combined forecast y is defined depending on the observed data with data size $\mathrm{T}\left(\mathrm{D}=\left[\mathrm{y}_{\mathrm{obs} 1}, \ldots \ldots ., \mathrm{y}_{\mathrm{obs}} \mathrm{T}\right]\right)$ and $\mathrm{K}$-model forecasts $\left(\mathrm{f}_{\mathrm{k}}\right)$ as follows:

$$
p(y \mid D)=\sum_{k=1}^{K} p\left(f_{k} \mid D\right) \cdot p_{k}\left(y \mid f_{k}, D\right)
$$

where $\mathrm{p}\left(\mathrm{f}_{\mathrm{k}} \mid \mathrm{D}\right)$ is the posterior probability of $\mathrm{k}$ th model forecast for given observed data and defined as weight of the $\mathrm{k}^{\text {th }}$ model $\left(\mathrm{w}_{\mathrm{k}}\right)$. Sum of the related model weights adds up to 1 . The conditional PDF $\mathrm{p}_{\mathrm{k}}\left(\mathrm{y} \mid \mathrm{f}_{\mathrm{k}}, \mathrm{D}\right)$ is assumed to be normally distrubuted and centered at linear regression function of $a_{k}+b_{k} . f_{k}$ whose response variables are the observed ones. Expected value of BMA forecasts are given in Eq.(2).

$$
E[y \mid D]=\sum_{k=1}^{K} p\left(f_{k} \mid D\right) \cdot E\left[p_{k}\left(y \mid f_{k}, D\right)\right]=\sum_{k=1}^{K} w_{k} \cdot f_{k}
$$


Raftery et al. (2005) recommended maximization of log-likelihood function as objective function to define the parameters which are weights $\left(\mathrm{w}_{\mathrm{k}}\right)$ and variances of model forecasts $\left(\sigma_{\mathrm{k}}^{2}\right)$. The log-likelihood function is

$$
l(\theta)=l\left(w_{1}, \ldots, w_{k} ; \sigma_{1}, \ldots, \sigma_{k}\right)=\log \left[\sum_{k=1}^{K} w_{k} \cdot g\left(y \mid f_{k}, \sigma_{k}\right)\right]
$$

where $\mathrm{g}\left(\mathrm{y} \mid \mathrm{f}_{\mathrm{k}}, \sigma_{\mathrm{k}}\right)$ is the conditional PDF of $\mathrm{y}$ for given model forecasts and predicted variance. The term $\mathrm{g}\left(\mathrm{y} \mid \mathrm{f}_{\mathrm{k}}, \sigma_{\mathrm{k}}\right)$ is similar to $\mathrm{p}_{\mathrm{k}}\left(\mathrm{y} \mid \mathrm{f}_{\mathrm{k}}, \mathrm{D}\right)$ such that it is normally distributed as $\mathrm{N}\left(\mathrm{a}_{\mathrm{k}}+\mathrm{b}_{\mathrm{k}} . \mathrm{f}_{\mathrm{k}}\right.$, $\sigma_{\mathrm{k}}$ ). For calculation convenience of log-likelihood maximization, expactation-maximization (EM) procedure is employed. For detailed explanation of BMA and EM, readers are referred to Raftery et al. (2005).

Undoubtedly, the forecasts obtained after weighting the results of GCMs (either coarse or downscaled) cannot be completely trusted. But yet, according to Murphy et al., (2004) and Chen et al. (2017), assigning weights, and thus reducing the influence of some GCMs which do not perform as well as others, can help diminish the uncertainties stemmed from projecting stages. In connection with this issue, Smith and Chandler (2010) and Whetton et al. (2007) expressed that a model's facility to reflect past climates could be an essential criterion for simulating future climates. In this respect, weighting the individual models with respect to REF is an appropriate strategy for scenario period simulations.

The GCMs which are utilized in the study differ from each other with regard to capability of forecasting the climate for different time periods. For example, one can be better at predicting hot seasons whereas the other can be better at predicting cold seasons. Hence, observed T data and downscaled REF data were divided into dry (from April to September) and wet (from October to March) periods. Thus, 12 weights belonging to 12 GCMs for each separate period were obtained in each ensemble projection of the related meteorological station. The 
determined weights were integrated with three RCP scenarios separately. Moreover, it is possible to interpret prediction capabilities of GCMs after the determination of GCM weights, that is, better performing GCMs get higher weights in comparison to the other GCMs. Thus, probabilistic performances of climate models used in the study were evaluated and presented in the Results section.

There is another problem in the use of GCMs in that these models have inherent biases. Li et al (2010) stated in their study that complicated structure of atmosphere system and converting it to a more simplified model entail GCM biases. Although the climate models have been improved in the AR5 since the AR4, according to IPCC (2013), biases in T and P still exist in certain climate models. Moreover, statistical downscaling models such as ANN and LSSVM have an only aim that is to calibrate the related downscaling model parameters to minimize the error value. These models do not reckon with the reference climate properties and inherent biases of GCMs are not corrected consequently. Hence, a bias correction procedure was applied for all downscaled and ensemble projections to derive physically and climatologically plausible simulations.

To apply bias correction procedure, equidistant quantile mapping (EDQM) method which reckons cumulative distribution functions (CDFs) of data to reduce the bias values resulting from simulations. EDQM method takes into account two factors in addition to uncorrected projected model value to get the corrected one as follows:

$$
Y_{c o r r, i}=Y_{s c n, i}+\text { Factor }_{1}-\text { Factor }_{2}
$$

where $\mathrm{Y}_{\text {corr,i }}$ is the bias corrected value of the corresponding variable on the $\mathrm{i}^{\mathrm{t}}$ month for the related scenario, $\mathrm{Y}_{\mathrm{scn}, \mathrm{i}}$ is the uncorrected value of the corresponding variable on the $\mathrm{i}^{\text {th }}$ month for the related scenario (scn). The Factor 1 and Factor 2 are calculated as 


$$
\begin{gathered}
\text { Factor }_{1}=F^{-1}\left(F\left(Y_{s c n, i}, \theta_{\text {scn }, i}\right), \theta_{\text {observed }, i}\right) \\
\text { Factor }_{2}=F^{-1}\left(F\left(Y_{s c n, i}, \theta_{s c n, i}\right), \theta_{\text {historical }, i}\right)
\end{gathered}
$$

where $\mathrm{CDF}$ of each scenario value for the related month with respect to distributional function and parameters are obtained in both factors. EDQM is sharply separeted from quantile mapping (QM) method with this property, such that EDQM reckons with distributional parameters of both historical and future scenarios whereas QM takes into account the CDFs only with respect to distribution of historical scenario and maps onto observed one. The CDFs of each simulation on the related mont hare calculated by using PDF as follows:

$$
F\left(Y_{s c n, i} ; \theta_{s c n, i}\right)=\int_{-\infty}^{Y_{s c n, i}} f\left(x ; \theta_{s c n, i}\right) d x
$$

where $\mathrm{f}\left(\mathrm{x} ; \theta_{\mathrm{scn}, \mathrm{i}}\right)$ is the PDF of corresponding meteorological variable for given distribution parameters. Also, $\mathrm{F}^{-1}($.$) represents the inverse \mathrm{CDF}$ and $\theta_{\text {historicali, }}$ and $\theta_{\text {observed,i }}$ denotes the value of the distribution parameters of corresponding meteorological variable for the historical scenario and observed data, respectively.

The above-mentioned corresponding meteorological variable is $\mathrm{T}$ for this study. The bias corrected time series of $\mathrm{P}$ was already obtained from OK16. EDQM method requires fitting distribution functions for the time series, hence, the probability plot-correlation coefficient (PPCC) tests were applied to observed and downscaled T time series. As a result of the PPCC tests, it was determined that $\mathrm{T}$ time series were fitted to normal distribution, so the distribution parameters were mean and standard deviation for this application. For the sake of brevity, the results of the PPCC tests will not be given in the study. 


\subsection{Simulation of potential evapotranspiration and aridity index}

In the literature, there are several methods used for determination of the AI. Most of them determine the AI by using $\mathrm{P}$, PET or T data. One of them is $\mathrm{P}$ and $\mathrm{T}$ data user Köppen and Trewartha climate classification method which is used for definition of climate regime and prevalent vegetation type related to the climatic conditions. Another method is De Martonne's AI method in which $\mathrm{AI}$ is calculated with proportion of mean annual $\mathrm{P}$ to mean annual $\mathrm{T}$ plus $10^{\circ} \mathrm{C}$. The difference between mean annual PET and mean annual $\mathrm{P}$ over mean annual $\mathrm{P}$ is defined as Thornthwaite AI. Similarly, UNESCO (1979) expressed AI as the proportion of mean annual P to mean annual PET and same proportion was proposed by UNEP (1992). Difference between UNESCO (1979) and UNEP (1992) is the method of definition of PET. In UNESCO (1979) PET is defined by using standard Penman formula, while PET is defined by using Thornthwaite empirical equations in UNEP (1992). Different from those, AI is defined with mean annual net radiation, mean annual $\mathrm{P}$ and latent heat of evaporation by Budyko (1958). Upon examining the above-mentioned methods, they reflect correlative properties (Paltineanu et al., 2007), hence, in the study, it was found adequate to use UNEP (1992) aridity index for the calculation of AI by

$$
A I=P / P E T
$$

As mentioned above, PET is calculated by means of Thornthwaite formula in UNEP (1992). However, in the literature, Penman-Monteith (PM) method is introduced as standard PET calculation method such that it is considered as indirect measurement of PET beside lysimeter measurements. Although PM method is taken into consideration as the standard reference method, it can be unfeasible in certain regions due to the fact that PM requires large amount of data. It demands data such as average dew point temperature, several variants of radiation, pressure and wind speed such that they are highly possible to be unmeasured in a region or it is 
not possible to obtain them as continuously measured. The lack of input data of PM is problematic for Gediz Basin, too, hence it was decided to extract ERA-Interim reanalysis data sets required for PET calculation by Penman-Monteith. Okkan and Kiymaz (2019) already revealed that several input data of PM obtained from reanalysis data sets are compatible to observed data in Gediz Basin, thus, it is considered that reanalysis data sets have enough spatiotemporal reliability in terms of compatiblity to actual data of Gediz Basin. In order to project PET in accordance with RCPs, the PM method was simulated by calibrating coefficients of temperature-based Hamon (Ham), Blaney-Criddle (Bl-Cr) and Thornthwaite (Thw) methods and the performance of the best method was utilized for PET projections. The input of outperforming method is T projections derived under RCPs. Subsequently, AI and climatic regimes were defined for REF and scenario period, separately. To give an example, the similar coefficient adjustment practices were also implemented for radiation-based PET methods such as Hargreaves and Priestley-Taylor equations as in Tabari and Talaee (2011). The climatic regimes corresponding to AI intervals are listed in Table 2.

\section{Results}

\subsection{Possible changes in temperature}

\subsubsection{Statistical downscaling phase}

In the study, the projection studies were initialized by downcaling coarse-resolution re-analysis and GCM data to local scale. Prior to the downscaling, the time series of potential predictor and local-scale temperature were divided into equal time period for training and testing the models. When the results of ANN and LSSVM were compared, it was realized that statistical performances of both models were close to each other in the training phase. Hence, the decision was made about which downscaling model results to be used in terms of testing performances 
due to the fact that extrapolation capabilities of models are prominent in climate studies (Table 3). Subsequent to the determination of related parameters of better performing downscaling models, they were integrated with data of REF and RCP scenarios. Upon assessing the test results of the models for each station, both ANN and LSSVM models show 'very good' testing results at downscaling $\mathrm{T}$ for each station in terms of NS, RSR and PBIAS (please check qualitative evaluations of performance criteria from Moriasi et al. (2007)). In the decision phase of model selection, test results of better performing models were selected and utilized in the next process.

\subsubsection{Multi-model ensemble, bias correction and ultimate results}

In the downscaling application, the raw GCM data were integrated with calibrated and validated downscaling models which were selected individually for each station and it was obtained that statistical behavior of $\mathrm{T}$ series belonging to $12 \mathrm{GCMs}$ were different from each other. As stated before, this situation entails uncertainty in model selection and puts into trouble in decision. Hence, BMA method was utilized to produce weighted-average projections in which 12 GCMs were combined. For each station, observed data and historical projections of 12 GCMs were utilized and the time series were divided into wet and dry periods. In this process, each GCM had its own weight for wet and dry periods respectively. At the end, the expected values of multi-model ensembles for related wet and dry periods were derived and the long term monthly time series were reproduced by combining wet and dry periods. Same weights were used for RCP4.5, RCP6.0 and RCP8.5 scenarios respectively. The related weights were shown in Table 4 for each meteorological station. According to Table 4, BCC-CSM1.1 and HADGEM2-ES climate models have the highest weight values for wet and dry periods respectively. Due to the 
fact that the better the model performs, the higher weight value it gets, it can be interpreted that BCC-CSM1.1 and HADGEM2-ES climate models have the highest capability of representing the local temperature over Gediz Basin for wet and dry periods, respectively.

Subsequent to combination of twelve GCM results, EDQM method was utilized to eliminate the model biases. As seen in the sample of Foca meteorological station, the uncorrected REF simulation has different statistics and frequency distribution when compared to observed time series (Figure $2 \mathrm{a}$ and $\mathrm{b}$ ). In order to capture the climatological conditions of the study area, the model biases were corrected and it was obtained that the corrected historical $\mathrm{T}$ series were more compatible to the observed series (Figure 2c). Similar biased results were produced for other related meteorological stations and the related bias correction procedure were applied for all of them.

Upon evaluating the $\mathrm{T}$ projections for all meteorological stations, it is foreseen that mean annual T changes between $+1.26^{\circ} \mathrm{C}$ and $+2.80^{\circ} \mathrm{C}$ may occur over different regions of Gediz Basin. The maximum mean annual $\mathrm{T}$ increases for all concentration pathways are predicted in Salihli meteorological station as +1.94 , +1.95 and $+2.80^{\circ} \mathrm{C}$ for RCP4.5, RCP6.0 and RCP8.5, respectively. When the possible spatial changes in $\mathrm{T}$ are evaluated over Gediz Basin, it is obtained that the highest changes for all RCPs are expected in southern part of the basin and this situation spreads to the mid-northern part of the basin. In the eastern part of the basin, the expected temperature changes are around the calculated mean annual changes for entire basin (1.54, 1.60 and $2.18^{\circ} \mathrm{C}$ for RCP4.5, RCP6.0 and RCP8.5, respectively). Upon evaluating the westward change of amount of $\mathrm{T}$ increase, especially as of central part of the basin, the related amount of expected increase diminshes gradually. For entire basin, the mean annual $\mathrm{T}$ which is about $15.1^{\circ} \mathrm{C}$ in the $\mathrm{REF}$ is foreseen that it may increase to $16.7,16.8$ and $17.3^{\circ} \mathrm{C}$ for $\mathrm{RCP} 4.5$, RCP6.0 and RCP8.5, respectively. In addition to annual analysis of possible T changes, they 
were assessed in terms of seasonal periods. According to this assessment, the highest increase is expected in the summer season for all RCPs. The mean summer T which is about $25^{\circ} \mathrm{C}$ in the reference period may increase $1.87,1.74$ and $2.46^{\circ} \mathrm{C}$ for RCP4.5, RCP6.0 and RCP8.5 respectively. In autumn seasons, mean $\mathrm{T}$ of $15.9^{\circ} \mathrm{C}$ may increase $1.52,1.62$ and $2.44^{\circ} \mathrm{C}$ for RCP4.5, RCP6.0 and RCP8.5, respectively. The mean spring $\mathrm{T}$ is expected to increase 1.44, 1.52 and $1.99^{\circ} \mathrm{C}$, the mean winter $\mathrm{T}$ may increase $1.34,1.52,1.85^{\circ} \mathrm{C}$ for RCP4.5, RCP6.0 and RCP8.5, respectively. In the seasonal evaluation, it is realized that the temperature increase is directly proportional with respect to radiative forcing for winter, spring and autumn seasons while the mean temperature of RCP4.5 is higher than the mean temperature of RCP6.0 for summer season. Similar predictions were experienced in the monthly evaluations of $\mathrm{T}$ projections as well. The maximum $\mathrm{T}$ increase for both RCP6.0 and RCP8.5 is expected in October as $1.88^{\circ} \mathrm{C}$ and $2.68^{\circ} \mathrm{C}$ respectively, but on August for $\mathrm{RCP} 4.5$ as $2.03^{\circ} \mathrm{C}$ (Figure 3). In the study, hypothesis testing was made whether the mean annual, seasonal and monthly $\mathrm{T}$ changes are significant with respect to REF temperature of the related time periods. To do this, two sample t-tests were applied for the mean values of projected $\mathrm{T}$ series of annual, seasonal and monthly time periods (the significance level is .05). Consequently, it was deduced that all possible changes are statistically significant with respect to historical $\mathrm{T}$ for annual, seasonal and monthly time periods.

According to Dibike et al. (2007), one has to be at least induced that the downscaled values of any GCM can represent the historical characteristics of the $\mathrm{T}$ and $\mathrm{P}$ sensibly well in order to have assurance on GCM based projections. In the context of uncertainty analysis, MannWhitney U test, which was applied by Dibike et al. (2007) for the same concept, is used to determine whether the predictions produced after multi-model ensemble/bias correction procedure can reflect the observations covering the REF. The pairwise comparisons made by nonparametric tests result in that multi-model ensembling and bias correction strategy increases 
the p-value statistics for $\mathrm{P}$ and $\mathrm{T}$ on both monthly and yearly basis when compared to individual models undergone no treatment (not illustrated here). An exemplary uncertainty analysis screening statistically downscaled P was presented by the same authors (see OK16).

The above-mentioned uncertainty analysis used in the study was only performed for the REF, similar to that in Dibike et al (2007). However, the decomposition of total uncertainty in RCP based projections was not addressed in the study. In other words, supposing that the projection is made up of three stages applied (i.e. GCMs, emission scenarios, and downscaling models), it has not been identified how uncertainties are propagated as the stages proceed in produced projections.

\subsection{Possible changes in potential evapotranspiration}

The similar assessments for $\mathrm{T}$ projections were made for PET forecasts which were projected through T-based empirical equations modified in accordance with PM method. In order to handle the provision of input data demanded by PM method, ERA-Interim reanalysis data sets were utilized and PET estimations were obtained for the past period. Ham, Bl-Cr and Thwbased PET equations were modified by adjusting the coefficients of the formulas depending on PM estimations so that PET estimations were derived for RCP scenarios by integrating $\mathrm{T}$ projections into adjusted T-based formulas. The level of biases of the predictions derived from recalibrated equations against the PM predictions was questioned by criteria such as $\mathrm{R}^{2}$, NS, RSR, which were also assessed in the investigations of downscaling model performances. It was found unnecessary to give the PBIAS results due to the fact that each model derived PBIAS values close to zero. As a result of the calibrations carried out separately on 20 meteorological stations, it is deduced that the predictions of modified Hamon equation adequately represent those of reference method in terms of several performance measures denoted in Table 5. Then, 
the T-based PET function consisting of these coefficients mentioned in Table 5 was utilized to convert the downscaled $\mathrm{T}$ projections to PET values within the scope of RCP scenarios. According to the calculations made for scenario period, there is no region in Gediz Basin where the mean annual and seasonal PET are expected to decrease. On the monthly basis, PET decreases are generally expected only in January, February and March in major part of the basin. The minimum mean annual increases are foreseen in Sarigol region as $4.2 \%$ for both RCP4.5 and RCP6.0 and 5.6\% for RCP8.5, while the maximum increases are expected in Demirci region, where relatively low PET was estimated in REF, as $7.4 \%$ and $10.2 \%$ for the related mid and high stablization scenarios, respectively. When the PET column of Figure 5 is evaluated, it can be seen that the minimum PET increases may occur in the southern and western parts of the basin (Sarigol, Alasehir, Foca regions and apart from these Simav region in the north). Moreover, the related increasing rate is foreseen to be exacerbated northeastwardly. The maximum increases are expected in the northern parts of the basin (Demirci and Gediz regions). As is the case with $\mathrm{T}$ projections, the PET changes were evaluated in terms of time periods for the entire basin. The mean total annual PET which is $1141.8 \mathrm{~mm}$ in REF, is expected to increase $5.5 \%, 5.6 \%$ and $7.7 \%$ for RCP4.5, RCP6.0 and RCP8.5, respectively. For the seasonal periods, the mean total PET in autumn season whose REF value is $219 \mathrm{~mm}$ is expected to have maximum increase as $11.7 \%, 12.1 \%$ and $15.2 \%$ for RCP4.5, RCP6.0 and RCP8.5, respectively. The increase rate of $5.6 \%$ in winter and summer seasons and $0.81 \%$ in spring season for RCP4.5, the increase rate of $6.8 \%, 1 \%, 5.4 \%$ and $9 \%, 2.6 \%, 7.2 \%$ for RCP6.0 and RCP8.5 scenarios of winter, spring and summer seasons, respectively are foreseen in the scenario period. The maximum increase rate of PET is expected to occur on November for all of RCPs as in between $25 \%$ and $31 \%$ (see Figure 4 ). In order to analyze whether the possible PET changes are statistically significant, two sample t-tests were applied (the significance level is .05) as tested in the phase of $\mathrm{T}$ simulation. According to the t-tests, possible annual changes for all RCPs are 
statistically significant. The changes of winter, summer and autumn seasons are expected to be as statistically significant for all RCPs but only in spring season, PET is foreseen not to deviate significantly throughout the basin. The statistically significant changes are expected for the months between May and December in all RCPs, for April in RCP8.5 scenario. It is not predicted any statistically significant changes for the rest of the months.

\subsection{Future aridity index}

In the study, the PET simulations for 2015-2050 scenario period were derived for estimating future AI. As known, UNEP AI is the function of mean annual P and mean annual PET. Prior giving results about $\mathrm{AI}$, it will be informed briefly from OK16 about the mean annual P simulations over Gediz Basin. According to data utilized from OK16; it is predicted 8.2\%, $10.2 \%$ and $17.2 \%$ decreases throughout the basin for RCP4.5, RCP6.0 and RCP8.5, respectively. A westward expansion of increasing absolute $\mathrm{P}$ decrease is foreseen and the absolute changes of possible decreases are maximum in Menemen region for all RCPs. The sharpest decreases are expected in mid-southern and western parts of the basin (Menemen, Foca, Koprubasi, Sarigol, Salihli regions).

Due to the fact that it is expected in the future that there is no region where mean annual P may increase, mean annual T may decrease and mean annual PET may decrease, the AI over Gediz Basin is expected to tend to decrease in the scenario period. In REF, the DSH climate regime is observed in the eastern and northeastern parts of the basin. SA climate regime prevails in the major parts of the basin including central, western and southern regions. The lowest long-term AI values of 0.35 are calculated for Sarigol and Alasehir regions and 0.36 for Menemen region such that they are located in southern and western parts of the basin, respectively. The SH climate regime is observed in Simav up northeast and in Kemalpasa region up southwest such 
that Simav has the highest long-term AI (0.81) in REF. The long-term AI is calculated as 0.46 for the entire basin which means SA regime exists in the period 1980-2005. When examined region by region, $65 \%$ of the basin has the SA regime, $25 \%$ of the basin has the DSH regime and the $\mathrm{SH}$ regime is experineced in the rest of the basin. On yearly basis, only in $4 \%$ of the time period 1980-2005, the AI gets the values between 0.65 and 1.0 which corresponds to SH climate characteristics and in $38 \%$ of the time period, the AI gets the values between 0.5 and 0.65 corresponding to DSH climate characteristics. SA climate state arises in $58 \%$ of the time period such that it represents the main climatic characteristics of the basin for REF.

In the AI simulations, it is obtained that the AI is expected to decrease gradually with respect to REF for all regions of the basin as the radiative forcing increases. In other words, for all RCP scenarios, it is not foreseen any $\mathrm{H}$ climate regime which can be observed in the scenario period in any of the regions of Gediz Basin. As in REF, in western, central and southern parts of the basin, SA climate regime is foreseen to resume in the scenario period for all RCPs. In RCP4.5 scenario, DSH climate regime is expected to prevail in the eastern and northeastern parts of the basin and SH climate regime is expected to occur in Simav and Kemalpasa regions but with lower AI values. As experienced in the past period, Simav region is foreseen to be the most humid region in the future for all RCPs (with AI of 0.71, 0.69, 0.63 for RCP4.5, RCP6.0 and RCP8.5, respectively). In RCP6.0 scenario, the climate regimes have the analogous spread as in the RCP4.5 but under drier climatic conditions than those of REF and RCP4.5 scenario. In RCP8.5, it is expected that dryness may have more impact on the basin and there may be no region where SH climate regime prevails. The results of RCP8.5 scenario reveals that the most humid regions of basin, Simav and Kemalpasa, may have DSH cliamtic conditions for the future long-term. In addition to Simav and Kemalpasa, it is expected Demirci region to experience DSH climate regime and SA climate conditions are expected to dominate in the rest of the basin. On the regional basis, $10 \%$ of the basin has the $\mathrm{SH}$ climate regime for both RCP4.5 and RCP6.0 
scenarios as in REF, and it is not expected to be seen in any region of the basin in RCP8.5. The DSH climate regime is foreseen to occur in regions representing $10 \%$ and $15 \%$ of the basin in mid and high stabilization scenarios, respectively. Furthermore, SA climate regime is expected dominate over the basin with rate of $80 \%$ for both RCP4.5 and RCP6.0 scenarios and $85 \%$ for RCP8.5. The long-term AI for entire Gediz Basin is calculated as 0.40, 0.39 and 0.35 which are pronounced as SA climate regime for all of RCPs and SA conditions are expected to be dominant over the entire basin in the future (Figure 5). On yearly basis, $\mathrm{SH}$ climate state is not expected to occur in throughout the scenario period, DSH climate state may occur in the $17 \%$, $22 \%$ and $6 \%$, and SA climate state may occur in the $83 \%, 75 \%$ and $92 \%$ of the scenario period for RCP4.5, RCP6.0 and RCP8.5 scenarios respectively. In addition, A climatic states which correspond to AI values lower than 0.2 are possible to occur throughout the scenario period with the rate of $3 \%$.

\section{Discussion and Conclusions}

In this work, a projection algorithm was set up to analyze how AI over Gediz Basin may change until the end of the mid-21st century. In order to do this implementation, a statistical downscaling procedure was applied so that coarse-resolution twelve GCMs data of three RCPs can be downscaled to the local scale. Following the downscaling stage, a multi-model ensemble and bias correction strategy was applied through BMA and EDQM methods to achieve less uncertain, more robust and unbiased $\mathrm{T}$ simulations. Ultimately, temperature projections with respect to three RCPs over Gediz Basin were obtained. The T-based Ham, Bl-Cr and Thw equations were modified with respect to PET estimates obtained through PM method and hence, the data underlying the PET simulations were produced. The T simulations derived for three different RCPs were integrated with outperforming Ham-based PET equations and PET 
simulations which may occur over Gediz Basin were obtained for the related concentration pathways. Subsequently, the AI and climatological regime which are expected over Gediz Basin were predicted for the sceanrio period.

Statistical downscaling techniques are very useful methods to downscale raw GCM data to local scale, espicially in $\mathrm{T}$ downscaling. There are several studies made for different regions in the world in which statistical downscaling methods derive very strong results for $\mathrm{T}$ downscaling (Chu et al., 2010; Jeong et al., 2012). In the study, ANN and LSSVM machine learning methods were employed to downscale $\mathrm{T}$ by utilizing surface temperature variable of ERAInterim reanalysis data as input. They both showed results classified as "very good" for all meteorological stations, in fact, they have very high values of $\mathrm{R}^{2}$ as $0.98-0.99$, NS as $0.98-0.99$ and very low values of RSR as $0.08-0.12$ for both calibration and verification stages of the models. What is more, the best downscaling results derived by the models in terms of verification performances and the oppurtunity was constituted to utilize the results of both ANN and LSSVM. Hence, it is thought that these results are very consistent for the temperature simulations prepared for the study area.

Individual GCMs have uncertainty originated from different aspects such as initial and boundary condition uncertainities, problems in theoretical definition of the global climate system and parameter uncertainties (Knutti, 2008). In the work, 12 GCMs were utilized instead of employing individual climate model in order to capture the varying notions of research centers which developed the related climate models. However, it is tedious to decide which climate models should be selected for the study area. In order to clear up this problem, the multi-GCM strategy developed for the study area was considered to be the key solution through BMA model which assigns probabilistic weight for each GCM so that one deterministic result was obtained for each RCP. Moreover, by means of weight assignment, BMA model gave us 
some idea about which climate model can be more predictive for Gediz Basin with respect to different periods such as wet and dry. With this approach, BCC-CSM1.1 and HADGEM2-ES climate models can be thought as stochastically better explanatory models in comparison to the other ones for wet and dry periods, respectively.

The GCMs have inherent biases with respect to $\mathrm{P}$ and $\mathrm{T}$ such that they exist more in the predictions made for $\mathrm{P}$ due to the fact that the behaviour of $\mathrm{P}$ is more complex in comparison to that of temperature. In OK16, the $\mathrm{P}$ biases were corrected through quantile mapping (QM) method where frequencies of model predictions are assigned with respect to distribution parameters of REF simulation and mapped onto the observed ones. QM method is appropriate to utilize in $\mathrm{P}$ simulations, however, it may overestimate monthly temperature in so far as the future temperature are expected to exceed historical range and the distribution does not change for the future adjustments. Hence, EDQM in which simulation distribution is taken into consideration was utilized in the study and obatined physically conceivable $\mathrm{T}$ simulations were derived.

Although PM is introduced as reference method in the literature, its usage is sometimes troublesome on account of lack of continuously observed data required by PM. Thus, an efficient strategy was implemented in the study by converting T-based methods in accordance with PM estimates. It enabled us to project PET by locally calibrated methods built upon downscalable T variable which were compatible to mechanism of PM. Among the T-based methods, Hamon method shows the best performance in which it utilizes only the duration of day light component in addition to $\mathrm{T}$.

It is expected Gediz Basin to have an increasing trend of T and PET in the scenario period. The highest change in mean annual change is expected to take place in the western, central and southern part of the basin. As known, T is an effective factor causing PET, hence, it is natural 
that maximum increases in PET are expected in western, central and southern parts where the most important water resources of Gediz Basin such as Demirkopru Dam, Marmara Lake, Gordes Dam, Avsar Dam and Buldan Dam are existing. Moreover, the irrigated fields are extending from southern part to western part of the basin. When it is thought that the mean areal $\mathrm{P}$ over these parts is expected to decrease, it may be inevitable that the irrigation water requirements may increase in the future. There is another study by Ozkul (2009) prepared for future climate of Gediz Basin. Overall, in Ozkul (2009), the GCMs of B2 and A2 emmision scenarios of TAR and AR4 were utilized. According to T simulations (used only four meteorological stations), $1.2^{\circ} \mathrm{C}$ and $2^{\circ} \mathrm{C}$ changes by 2050 were predicted in $\mathrm{B} 2$ and $\mathrm{A} 2$ scenarios, respectively. B2 and A2 scenarios have similarities with RCP4.5 and RCP6.0, so, when the related simulations are compared to those of prepared for this study, there are $+0.35^{\circ} \mathrm{C}$ and $-0.4^{\circ} \mathrm{C}$ differences between this study and Ozkul (2009). Furthermore, when mean annual PET results were compared for Menemen and Manisa stations (only the results of two meteorological stations are available) increases of $16 \%$ for B2 and 17\% for A2 are expected in Menemen station and 15\% increase is expected in Manisa station for both B2 and A2 scenarios, respectively. In this work, change of $6.2 \%$ and $6.5 \%$ in Menemen and $5.3 \%$ and $5.4 \%$ for Manisa are expected for RCP4.5 and RCP6.0 scenarios, respectively. Although the results of the related study support this study, use of different methodology, the up-to-date scenarios and comprehensive examination of basin with 20 meteorological stations add this study novelty. In addition to Ozkul (2009), this study captures analogous results with Tabari and Willems (2018a) in which they release that espicially western Turkey (also covering Gediz Basin) may experience decreases in P by greater than $20 \%$ at the end of the 21 st century. Moreover, they foresee that number of dry days and longest dry spell expected in the future may increase in the region. What is more, as claimed in studies of Zarghami et al. (2011) and Nastos et al. (2013) 
prepared for Azerbaijan, Iran and Greece which are neigboring countries of Turkey, they predict drier climate conditions than those of past period as expected in our study.

In the literature, some references are related to topics such as signal-to-noise $(\mathrm{S} / \mathrm{N})$ interpretation and uncertainty decomposition theory in climate change impact assessments (Hawkins and Sutton, 2010, Tabari and Willems, 2018b) in which the sources of climatic variability are discussed. In this study, the issues such as detection of uncertainty stemmed from climate models or GHG concentration scenarios were not covered, however, internal variability was simply tackled in this section in brief. The coefficient of variation (CV) which can be considered as reciprocal of $\mathrm{S} / \mathrm{N}$ ratio was calculated for REF and RCPs and the reasons of AI variability was queried. Asfaw et al. (2018) and Hare (2003) have expressed that a higher value of the $\mathrm{CV}$ is the indicator of larger variability. Instead of checking $\mathrm{S} / \mathrm{N}$ ratios, inter-annual $\mathrm{CV}$ statistics for T, P and AI were examined. Since the study is on the subject of projected aridity, it was investigated the extent to which the variability in the AI was affected by the variations in $\mathrm{P}$ and $\mathrm{T}$. At this stage, the inter-annual $\mathrm{CV}$ values calculated for the AI were analyzed by means of scattering diagrams (not presented here) in response to that of $\mathrm{P}$ and $\mathrm{T}$, respectively. The obtained results demonstrated that inter-annual variability in the AI is more directed by $\mathrm{P}$ variability. Although it is monitored that the increase in inter-annual variability of $\mathrm{T}$ has an inverse effect on AI's variability, the correlations between them are not statistically significant. The main reason for this is that the trend in annual average $\mathrm{T}$ indicates a significant increase during the existed period, while the inter-annual irregularities in the $\mathrm{P}$ point out both notrending and the large CV. In our future works, we have in view to deal the methodologies, which were effectively applied by Tabari and Willems (2018b), to decompose total uncertainty into uncertainty originated from various stages of climate change projections. 
Another noticable finding obtained in the study is that the results of RCP4.5 and RCP6.0 are very close to each other. As known, PET is the function of $\mathrm{T}$ and $\mathrm{AI}$ is that of $\mathrm{P}$ and PET. Hence, it was decided by the authors to check out how raw GCM data of $\mathrm{P}$ and $\mathrm{T}$ vary for RCP4.5 and RCP6.0 scenarios. When examined the raw data of twelve GCM data, the similar close values draw attention for the scenario period. Overall, approximately the difference of $18 \mathrm{~mm}$ which corresponds to $0.035 \%$ of the raw historical data in mean annual $\mathrm{P}$ and of $+0.1{ }^{\circ} \mathrm{C}$ in mean annual $\mathrm{T}$ are projected by the climate models in the grids of stuyd area. The range increases between the years $2051-2100$ with the difference of $-20 \mathrm{~mm}(0.04 \%$ of raw historical data) and $+0.4^{\circ} \mathrm{C}$ are projected in mean annual $\mathrm{P}$ and mean annual $\mathrm{T}$, respectively. When the emission scenarios of AR5 is taken into consideration, the difference of greenhouse gas emmision between the scenarios RCP4.5 and RCP6.0 are increasing right after half of the 21st century. Hence, it is logical to derive close results between RCP4.5 and RCP6.0 scenarios in the projections made for first half of the 21 st century. Moreover, there are another studies made in different regions of the world such as India (Chaturvedi et al., 2012) and North America (Swain and Hayhoe, 2015) in which close results were derived for RCP4.5 and RCP6.0 scenarios.

Upon evaluating the all simulations, it is obvious that negetive effects of climate change on Gediz Basin are expected in terms of aridity. In the past, Gediz Basin experienced three types of climate regime as SH, DSH and SA in various regions of the area. By the reason of possible negative effects of future climate on humid regions, it is expected these regions to have drier spells and conversion of the climate regime into DSH and SA in Gediz Basin until the end of the mid-21st century. In terms of long-term AI, the climate regime in the REF is SA and this situation is not expected to change according to all of the RCPs. However, the values of AI which are calculated with respect to increasing GHG emission scenarios signify climate states forcing the A climate zone may come into existence in the conditions of RCPs. In the 
pessimistic scenario, it seems that SA climate regime may overwhelmingly dominate the study area. When assessed in regional basis, the driest parts of the region may exist in the lower Gediz Basin where Avsar and Buldan irigation dams are operated for the agricultural fields. Moreover, the central and western parts of the basin where the other water resources exist are in the tendency of being in SA climate zone. Bannayan et al. (2010) made a study about the correlation between agricultural productivity and AIs in Iran, and found a positive correlation between grain yield and AI. Hence, due to the fact that Gediz Basin is a region where agricultural activities are carried out intensely, it is recommended by the authors that a study should be made about the how the agricultural productivity may change in the future with repsect to aridity for the sustainability of agricultural sector.

\section{Declarations}

\section{Funding}

The research leading to these results received funding from The Scientific and Technological Research Council of Turkey (TUBITAK) under Grant Agreement No 114 Y796.

\section{Conflict of interests}

The authors have no conflicts of interest to declare that are relevant to the content of this article.

\section{Data and Code Availability Statement}

The data that support the findings of this study are available from TUBITAK but restrictions apply to the availability of these data, which were used under licence for the current study, and so are not publicly available. Data and codes are however available from the authors upon reasonable request and with permission of TUBITAK. 


\section{Author's Contribution}

All authors contributed to the study conception and design. Material preparation, data collection and analysis were performed by Umut Kirdemir and Umut Okkan. The first draft of the manuscript was written by Umut Kirdemir and all authors commented on previous versions of the manuscript. All authors read and approved the final manuscript.

\section{Ethics Approval}

All procedures performed in studies involving human participants were in accordance with the ethical standards of the institutional and/or national research committee and with the 1964 Helsinki declaration and its later amendments or comparable ethical standards.

\section{Consent to participate}

Informed consent was obtained from all individual participants included in the study.

\section{Consent for publication}

The authors has consented to the submission of the manuscript to the journal. 


\section{References}

Anandhi, A., Srinivas, V. V., Nanjundiah, R. S., \& Kumar, D. N. (2008). Downscaling precipitation to river basin in India for IPCC SRES scenarios using support vector machine. International Journal of Climatology, 28(3), 401-420.

Asfaw, A., Simane, B., Hassen, A., \& Bantider, A. (2018). Variability and time series trend analysis of rainfall and temperature in northcentral Ethiopia: A case study in Woleka subbasin. Weather and Climate Extremes, 19, 29-41. https://doi.org/10.1016/j.wace.2017.12.002

Bannayan, M., Sanjani, S., Alizadeh, A., Lotfabadi, S. S., \& Mohamadian, A. (2010). Association between climate indices, aridity index, and rainfed crop yield in northeast of Iran. Field Crops Research, 118(2), 105-114. https://doi.org/10.1016/j.fcr.2010.04.011

Budyko, M. I. (1958). The heat balance of the Earth's surface. Washington, DC.

Chaturvedi, R. K., Joshi, J., Jayaraman, M., Bala, G., \& Ravindranath, N. H. (2012). Multimodel climate change projections for India under representative concentration pathways. Current Science, 103(7), 791-802.

Chen, J., Brissette, F. P., Lucas-Picher, P., \& Caya, D. (2017). Impacts of weighting climate models for hydro-meteorological climate change studies. Journal of Hydrology, 549(October), 534-546. https://doi.org/10.1016/j.jhydrol.2017.04.025

Chu, J. T., Xia, J., Xu, C. Y., \& Singh, V. P. (2010). Statistical downscaling of daily mean temperature, pan evaporation and precipitation for climate change scenarios in Haihe River, China. Theoretical and Applied Climatology, 99(1-2), 149-161. https://doi.org/10.1007/s00704-009-0129-6

Dascălu, S. I., Gothard, M., Bojariu, R., Birsan, M. V., Cică, R., Vintila, R., ... Mic, R. P. 
(2016). Drought-related variables over the Bârlad basin (Eastern Romania) under climate change scenarios. Catena, 141, 92-99. https://doi.org/10.1016/j.catena.2016.02.018

Dibike, Y. B., Gachon, P., St-Hilaire, A., Ouarda, T. B. M. J., \& Nguyen, V. T. V. (2007). Uncertainty analysis of statistically downscaled temperature and precipitation regimes in Northern Canada. Theoretical and Applied Climatology, 91(1-4), 149-170. https://doi.org/10.1007/s00704-007-0299-z

Fernandez, J. P. R., Franchito, S. H., Rao, V. B., \& Llopart, M. (2017). Changes in KoppenTrewartha climate classification over South America from RegCM4 projections. Atmospheric Science Letters, 18(11), 427-434. https://doi.org/10.1002/asl.785

Hare, W. (2003). Assessment of knowledge on impacts of climat change - contribution to the specification of the Art.2 of the UNFCCC. Wissenschaftlicher Beirat der Bundesregierung Globale Umweltveränderungen. Potsdam, Berlin.

Hawkins, E., \& Sutton, R. (2011). The potential to narrow uncertainty in projections of regional precipitation change. Climate Dynamics, 37(1), 407-418. https://doi.org/10.1007/s00382010-0810-6

IPCC. (2013). Climate Change 2013 - The Physical Science Basis. Contribution of Working Group I to the Fifth Assessment Report of the Intergovernmental Panel on Climate Change, 1535.

Jeong, D. I., St-Hilaire, A., Ouarda, T. B. M. J., \& Gachon, P. (2012). Comparison of transfer functions in statistical downscaling models for daily temperature and precipitation over Canada. Stochastic Environmental Research and Risk Assessment, 26(5), 633-653. https://doi.org/10.1007/s00477-011-0523-3

Schoof, J.T. (2013). Statistical downscaling in Climatology. Geography Compass, 7(4), 249- 
265. https://doi.org/10.1111/gec3.12036.

Knutti, R. (2008). Should we believe model predictions of future climate change? Philosophical Transactions. Series A, Mathematical, Physical, and Engineering Sciences, 366(1885), 4647-4664. https://doi.org/10.1098/rsta.2008.0169

Knutti, R., Abramowitz, G., Collins, M., Eyring, V., Gleckler, P. J., Hewitson, B., \& Mearns, L. (2010). Good Practice Guidance Paper on Assessing and Combining Multi Model Climate Projections. IPCC Expert Meeting on Assessing and Combining Multi Model Climate Projections, 15pp.

Kwon, W., Baek, H., \& Park, E. (2010). Probabilistic Regional Climate Change Projections Using Bayesian Model Averaging. IPCC Expert Meeting on Assessing and Combining Multi Model Climate Projections. Boulder, Colorado, USA.

Le Roux, R., Katurji, M., Zawar-Reza, P., Quénol, H., \& Sturman, A. (2018). Comparison of statistical and dynamical downscaling results from the WRF model. Environmental Modelling and Software, 100(December 2017), 67-73. https://doi.org/10.1016/j.envsoft.2017.11.002

Li, H., Sheffield, J., \& Wood, E. F. (2010). Bias correction of monthly precipitation and temperature fields from Intergovernmental Panel on Climate Change AR4 models using equidistant quantile matching. Journal of Geophysical Research Atmospheres, 115(10). https://doi.org/10.1029/2009JD012882

Lin, L., Gettelman, A., Fu, Q., \& Xu, Y. (2018). Simulated differences in 21st century aridity due to different scenarios of greenhouse gases and aerosols. Climatic Change, 146(3-4), 407-422. https://doi.org/10.1007/s10584-016-1615-3

Maliva, R., \& Missimer, T. (2012). Arid Lands Water Evaluation and Management, 
Environmental Science and Engineering. Springer Berlin Heidelberg. https://doi.org/10.1007/978-3-642-29104-3_2

Marengo, J. A., \& Bernasconi, M. (2015). Regional differences in aridity/drought conditions over Northeast Brazil: present state and future projections. Climatic Change, 129(1-2), 103-115. https://doi.org/10.1007/s10584-014-1310-1

Miao, C., Duan, Q., Sun, Q., \& Li, J. (2013). Evaluation and application of Bayesian multimodel estimation in temperature simulations. Progress in Physical Geography, 37(6), 727-744. https://doi.org/10.1177/0309133313494961

Min, S. K., Simonis, D., \& Hense, A. (2007). Probabilistic climate change predictions applying Bayesian model averaging. Philosophical Transactions of the Royal Society A: Mathematical, Physical and Engineering Sciences, 365(1857), 2103-2116. https://doi.org/10.1098/rsta.2007.2070

Moriasi, D. N., Arnold, J. G., Van Liew, M. W., Binger, R. L., Harmel, R. D., \& Veith, T. L. (2007). Model evaluation guidelines for systematic quantification of accuracy in watershed simulations. Transactions of the ASABE, 50(3), 885-900. https://doi.org/10.13031/2013.23153

Murphy, M. J., Sexton, H. D., Barnett, N., Jones, S., Webb, J., \& Collins, M. (2004). Quantification of modelling uncertainties in a large ensemble of climate change simulations. Nature, 430(7001), 768-772. https://doi.org/10.1038/nature02770.1.

Najafi, M. R., Moradkhani, H., \& Jung, I. W. (2011). Assessing the uncertainties of hydrologic model selection in climate change impact studies. Hydrological Processes, 25(18), 28142826. https://doi.org/10.1002/hyp.8043

Nastos, P. T., Politi, N., \& Kapsomenakis, J. (2013). Spatial and temporal variability of the 
Aridity Index in Greece. Atmospheric Research, 119, 140-152. https://doi.org/10.1016/j.atmosres.2011.06.017

NOAA National Centers for Environmental Information. (2019). State of the Climate: Global Climate Report for Annual 2018. https://www.ncdc.noaa.gov/sotc/global/201813.

Okkan, U., \& Inan, G. (2015). Statistical downscaling of monthly reservoir inflows for Kemer watershed in Turkey: Use of machine learning methods, multiple GCMs and emission scenarios. International Journal of Climatology, 35(11), 3274-3295. https://doi.org/10.1002/joc.4206

Okkan, U., \& Kirdemir, U. (2016). Downscaling of monthly precipitation using CMIP5 climate models operated under RCPs. Meteorological Applications, 23(3), 514-528. https://doi.org/10.1002/met.1575

Okkan, U., \& Kiymaz, H. (2019). Questioning of empirically derived and locally calibrated potential evapotranspiration equations for a lumped water balance model. Journal of Water and Climate Change. https://doi.org/10.2166/wcc.2019.292

Ozkul, S. (2009). Assessment of climate change effects in aegean river basins: The case of gediz and buyuk menderes basins. Climatic Change, 97(1), 253-283. https://doi.org/10.1007/s10584-009-9589-z

Paltineanu, C., Mihailescu, I. F., Seceleanu, I., Dragota, C., \& Vasenciuc, F. (2007). Using aridity indices to describe some climate and soil features in Eastern Europe: A Romanian case study. Theoretical and Applied Climatology, 90(3-4), 263-274. https://doi.org/10.1007/s00704-007-0295-3

Raftery, A. E., Gneiting, T., Balabdaoui, F., \& Polakowski, M. (2005). Using Bayesian Model Averaging to Calibrate Forecast Ensembles. Monthly Weather Review, 133(5), 1155- 
1174. https://doi.org/10.1175/MWR2906.1

Scheff, J., \& Frierson, D. M. W. (2015). Terrestrial aridity and its response to greenhouse warming across CMIP5 climate models. Journal of Climate, 28(14), 5583-5600. https://doi.org/10.1175/JCLI-D-14-00480.1

Smakhtin, V. U., \& Schipper, E. L. F. (2008). Droughts: The impact of semantics and perceptions. Water Policy, 10(2), 131-143. https://doi.org/10.2166/wp.2008.036

Smith, I., \& Chandler, E. (2010). Refining rainfall projections for the Murray Darling Basin of south-east Australia-the effect of sampling model results based on performance. Climatic Change, 102(3), 377-393. https://doi.org/10.1007/s10584-009-9757-1

Tabari, H., \& Talaee, P. H. (2011). Local Calibration of the Hargreaves and Priestley-Taylor Equations for Estimating Reference Evapotranspiration in Arid and Cold Climates of Iran Based on the Penman-Monteith Model. Journal of Hydrologic Engineering, 16(10), 837845. https://doi.org/10.1061/(asce)he.1943-5584.0000366

Tabari, H., \& Willems, P. (2018a). More prolonged droughts by the end of the century in the Middle East. Environmental Research Letters, 13(10). https://doi.org/10.1088/17489326/aae09c

Tabari, H., \& Willems, P. (2018b). Seasonally varying footprint of climate change on precipitation in the Middle East. Scientific Reports, 8(1), 2-11. https://doi.org/10.1038/s41598-018-22795-8

UNEP. (1992). World atlas of desertification. London.

UNESCO. (1979). Map of the world distribution of arid regions. Explanatory Note.

Whetton, P., Macadam, I., Bathols, J., \& O’Grady, J. (2007). Assessment of the use of current 
climate patterns to evaluate regional enhanced greenhouse response patterns of climate models. Geophysical Research Letters, 34(14), 1-5. https://doi.org/10.1029/2007GL030025

Willems, P., \& Vrac, M. (2011). Statistical precipitation downscaling for small-scale hydrological impact investigations of climate change. Journal of Hydrology, 402(3-4), 193-205. https://doi.org/10.1016/j.jhydrol.2011.02.030

WMO (2017). WMO Statement on the State of the Global Climate in 2017. World Meteorological Organization. https://doi.org/978-92-63-11212-5

Yang, T., Hao, X., Shao, Q., Xu, C. Y., Zhao, C., Chen, X., \& Wang, W. (2012). Multi-model ensemble projections in temperature and precipitation extremes of the Tibetan Plateau in the 21st century. Global and Planetary Change, 80-81, 1-13. https://doi.org/10.1016/j.gloplacha.2011.08.006

Yin, Y., Ma, D., Wu, S., \& Pan, T. (2015). Projections of aridity and its regional variability over China in the mid-21st century. International Journal of Climatology, 35(14), 43874398. https://doi.org/10.1002/joc.4295

Zarghami, M., Abdi, A., Babaeian, I., Hassanzadeh, Y., \& Kanani, R. (2011). Impacts of climate change on runoffs in East Azerbaijan, Iran. Global and Planetary Change, 78(34), 137-146. https://doi.org/10.1016/j.gloplacha.2011.06.003 


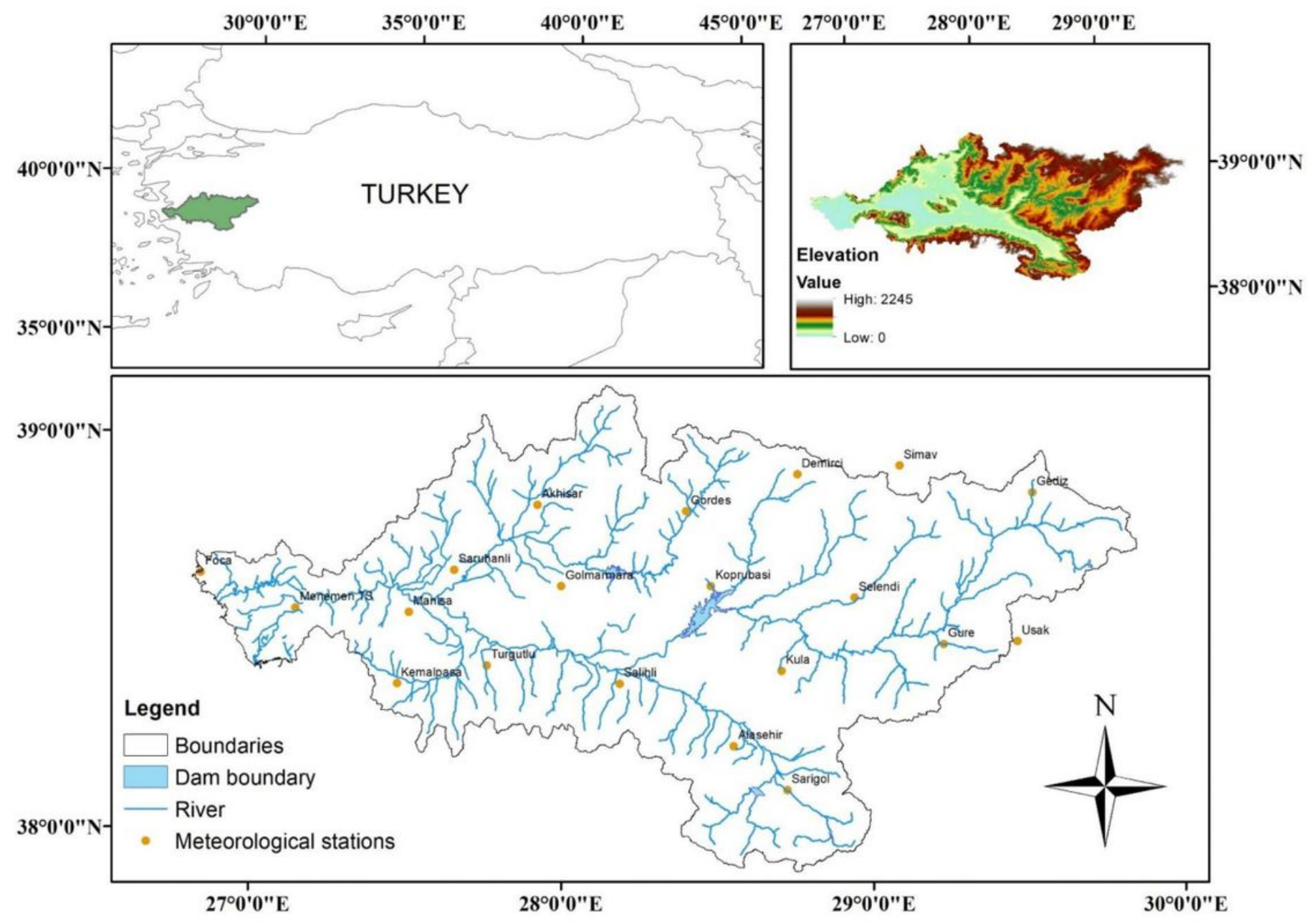

\section{Figure 1}

Location of Gediz Basin and meteorological stations with digital elevation map. Note: The designations employed and the presentation of the material on this map do not imply the expression of any opinion whatsoever on the part of Research Square concerning the legal status of any country, territory, city or area or of its authorities, or concerning the delimitation of its frontiers or boundaries. This map has been provided by the authors. 

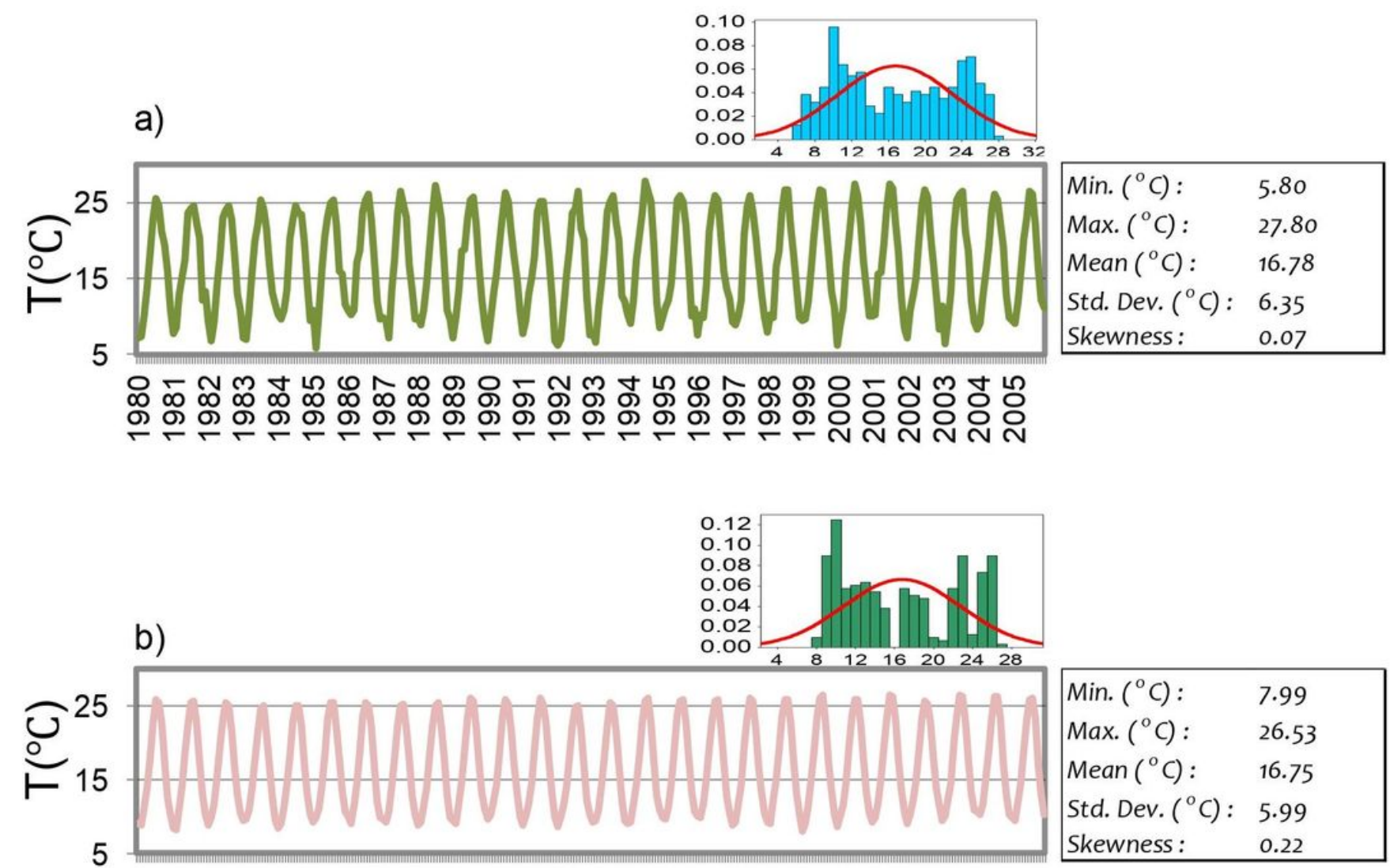

에 ద

Min. $\left({ }^{\circ} \mathrm{C}\right): \quad 7.99$

Max. $\left({ }^{\circ} \mathrm{C}\right): \quad 26.53$

Mean $\left({ }^{\circ} \mathrm{C}\right): \quad 16.75$

Std. Dev. ( ${ }^{\circ}$ ) : 5.99 


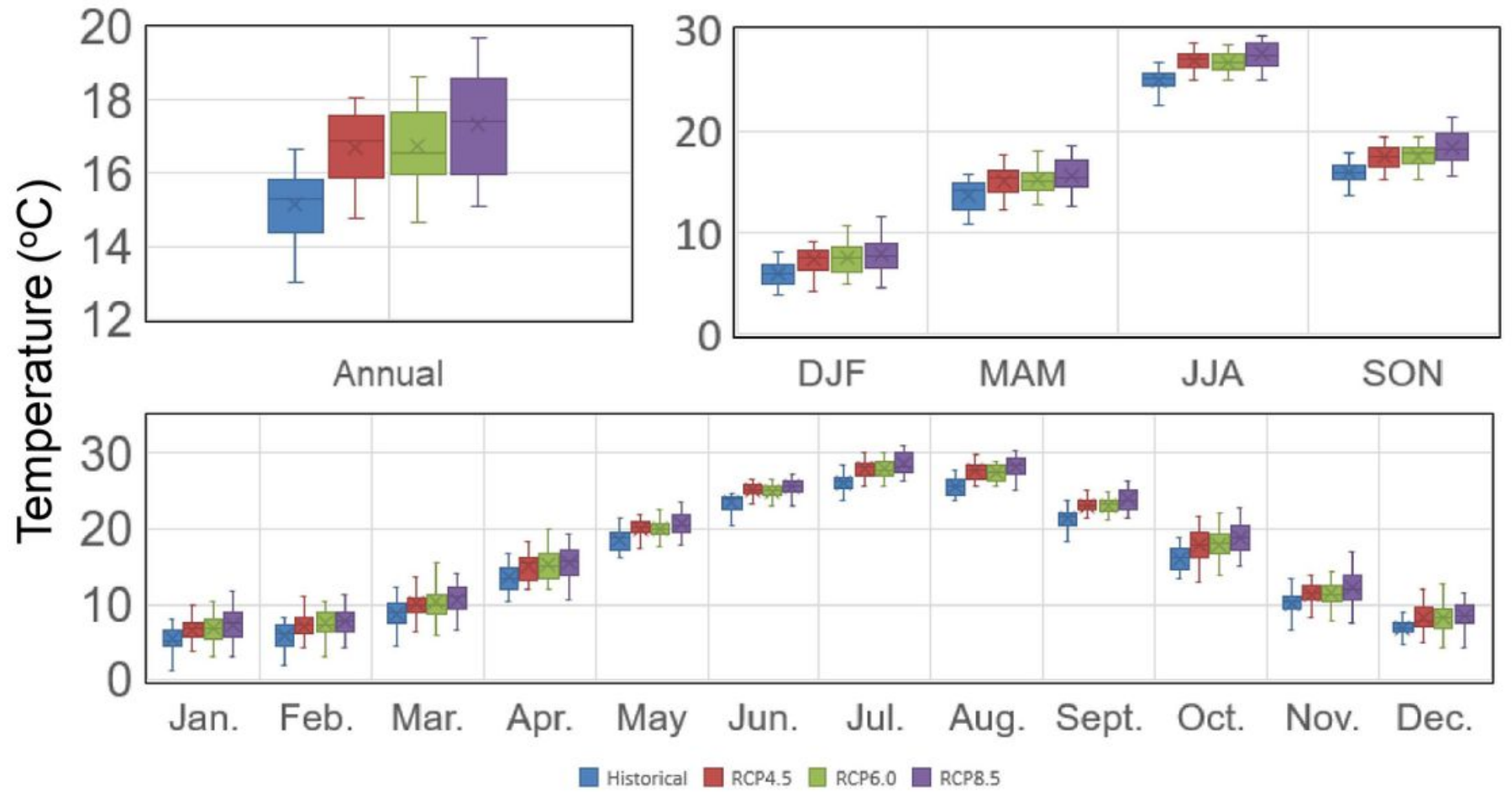

Figure 3

Box-plots of mean annual, seasonal and monthly temperature projected under historical, RCP4.5, RCP6.0 and RCP8.5 scenarios. The acronyms DJF, MAM, JJA and SON denote winter, spring, summer and autumn seasons, respectively. The labels in the horizontal axis of the seasonal box-plots are the initial letters of the months composing the related seasons.

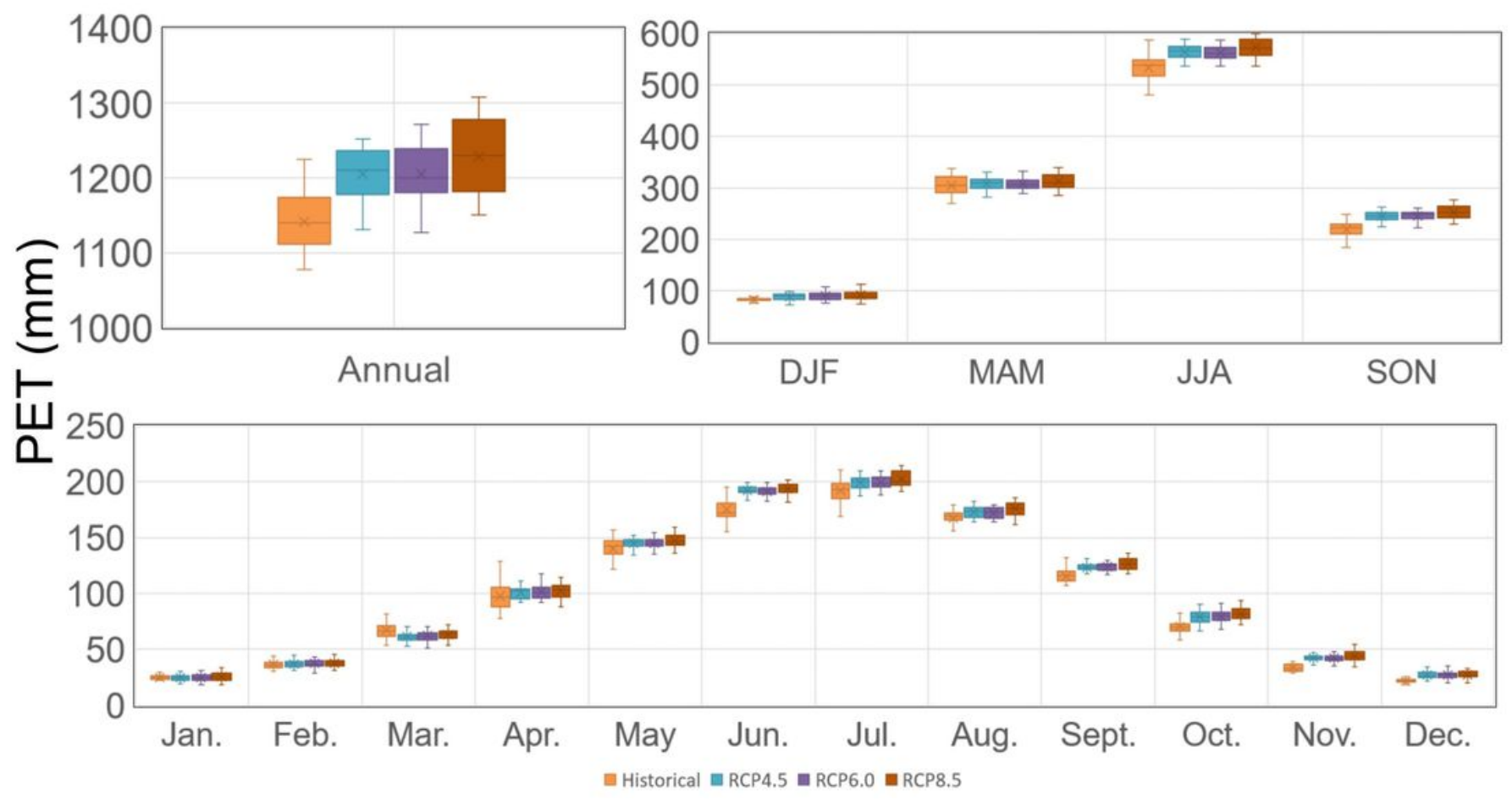




\section{Figure 4}

Box-plots of mean total annual, seasonal and monthly PET projected under historical, RCP4.5, RCP6.0 and RCP8.5 scenarios. The acronyms labeled in the seasonal box-plots are same as in Figure 3.

\section{$\mathrm{T}\left({ }^{\circ} \mathrm{C}\right)$}
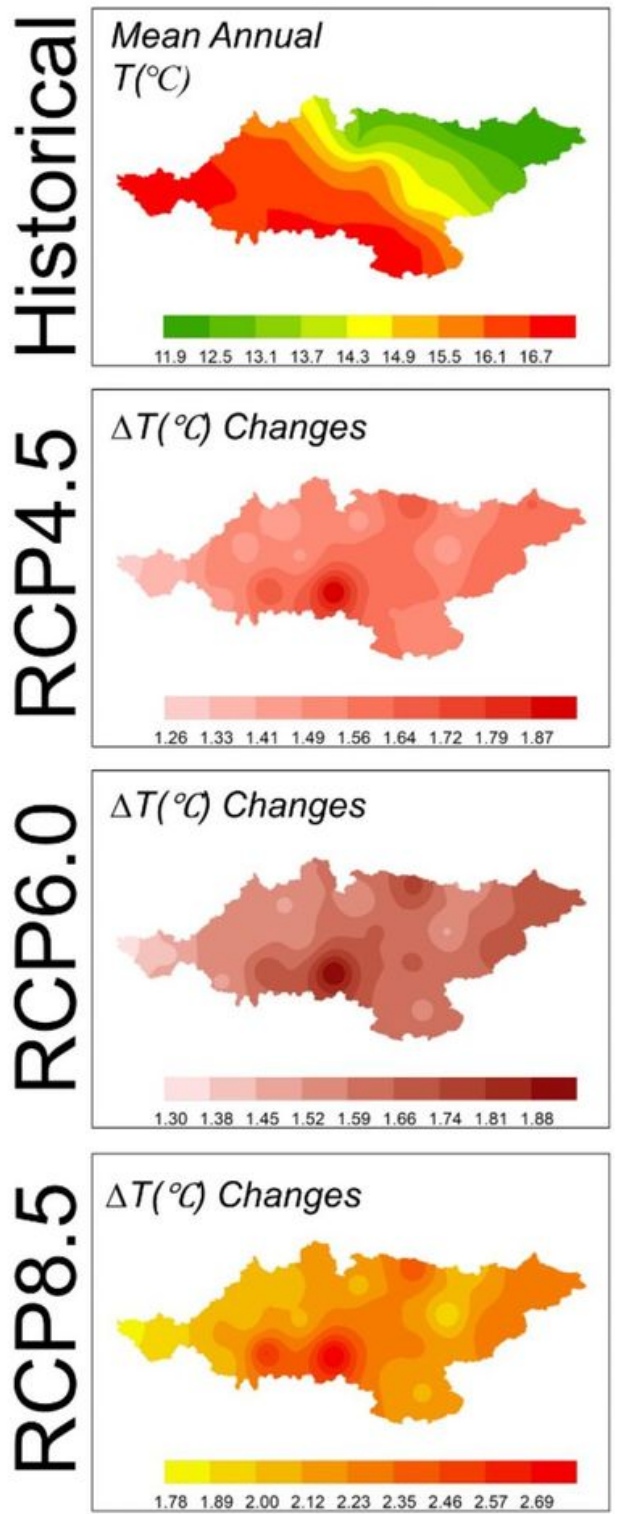

$\operatorname{PET}(\mathrm{mm})$
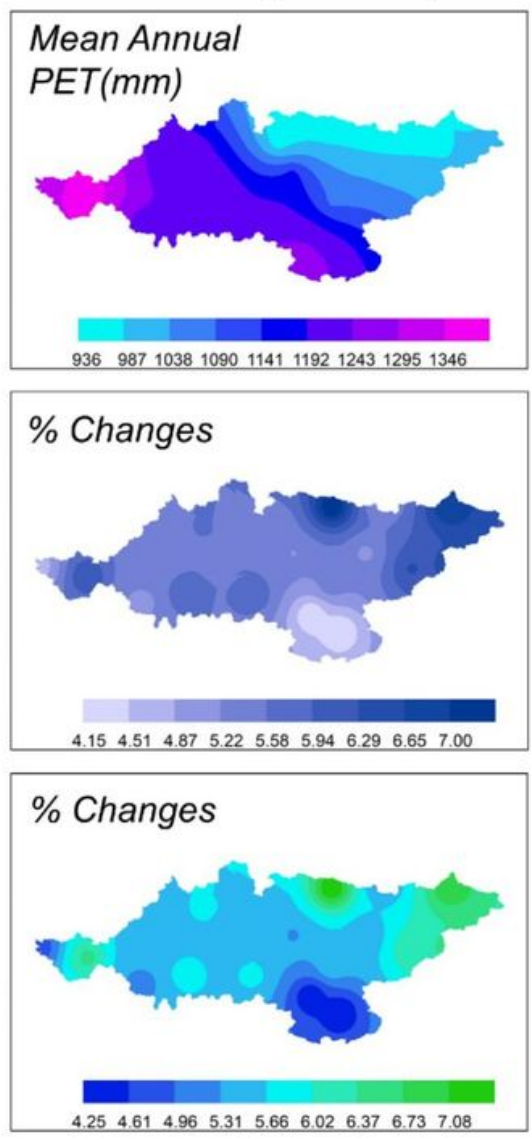

\section{$\%$ Changes}

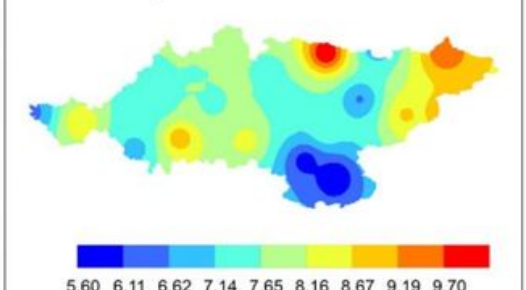

Al
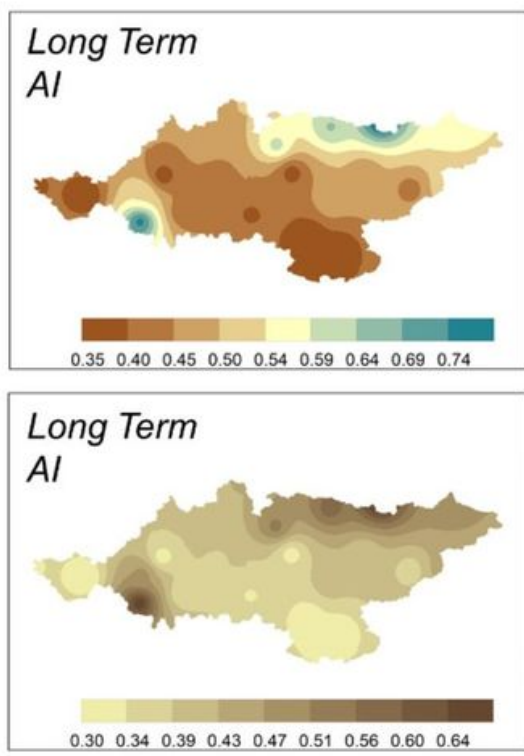

\section{Long Term \\ Al}

$\begin{array}{lllllllllll}0.29 & 0.34 & 0.38 & 0.42 & 0.46 & 0.50 & 0.54 & 0.59 & 0.63\end{array}$

\section{Long Term \\ Al}

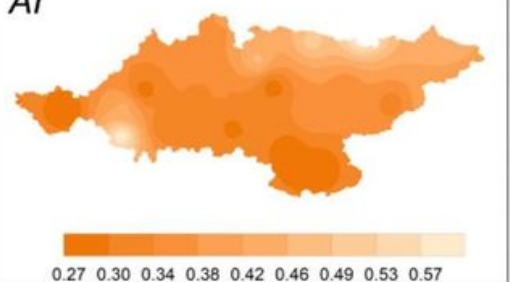

\section{Figure 5}

Spatial variability of mean annual T and PET and long-term Al over Gediz Basin. " $\Delta \mathrm{T}$ Changes" below the T column are equal to T_RCP-T_Historical and "\% Changes" below the PET column are equal to (( $\mathbb{P P E T}$ _RCP-CPET区_Historical))/पPET区_Historical . Note: The designations employed and the presentation of the material on this map do not imply the expression of any opinion whatsoever on the part of Research Square concerning the legal status of any country, territory, city or area or of its authorities, or concerning the delimitation of its frontiers or boundaries. This map has been provided by the authors. 


\section{Supplementary Files}

This is a list of supplementary files associated with this preprint. Click to download.

- Tables.docx 